\title{
ENCENAÇÕES DO FANTÁSTICO E DO ABSURDO EM VERONICA STIGGER ${ }^{1}$
}

Maria Fernanda Garbero de Aragão

\section{RESUMO:}

Este artigo é uma proposta de análise de dois contos de Veronica Stigger, tendo como hipótese a criação ficcional de contextos que, ao proporem uma intensa ruptura com o real, conduzem o leitor ao encontro de uma escritura fantástica. Para isso, fazem parte deste trabalho os textos "Tristeza e Isidoro", de Gran cabaret demenzial (Cosac Naify, 2007), e "Curta-metragem", contoroteiro dividido em duas partes, de Os anões (Cosac Naify, 2009). A partir da ideia de que nessas construções verifica-se uma descrença no diálogo como possibilidade de interação entre as personagens, observa-se a elaboração de outras perspectivas de mediações afetivas viáveis a esses cenários que, de certa forma, conduzem à estranheza. Ademais, uma proximidade entre o universo narrativo de Stigger e o Teatro do Absurdo também se configura, pois as inserções da desolação e da incomunicabilidade do homem moderno rompem com a dramaturgia tradicional e estabelecem novos sentidos. Ao avesso, as personagens aqui presentes experimentam o caos e encenam precárias sobrevivências entre acidentes, quedas e cacos.

\section{PALAVRAS-CHAVE:}

Ruptura; fantástico; absurdo; contemporaneidade.

\section{Introdução}

Começar pelas palavras finais de Tvetan Todorov $(1980)^{2}$, em Introdução à Literatura Fantástica, parece-nos um caminho interessante para pensar as fronteiras entre realidade e ficção no texto fantástico. De acordo com o crítico, "A operação que consiste em conciliar o possível e o impossível pode chegar a definir a palavra "impossível". E entretanto, a literatura é: eis aqui seu maior paradoxo." (TODOROV, 2003, p. 187).

O paradoxo da literatura, assim, permite rupturas e dissoluções de sentidos capazes de promoverem novas configurações acerca do provável, logo, das referências ao mundo real. As ressignificações que se operam no texto literário conduzem à compreensão de elementos que, na ficção, representam outras

\footnotetext{
$1 \quad$ Maria Fernanda Garbero de Aragão é doutora em Literatura Comparada pela Universidade do Estado do Rio de Janeiro e Professora Adjunta de Literatura Brasileira na Universidade Federal Rural do Rio de Janeiro.

2 A edição analisada neste artigo é de 2003, publicada pela editora Perspectiva.
} 
formas de ler o que poderíamos considerar, em seu aspecto amplo, diferentes realidades. Estas, por sua vez, são aceitas nesses textos, ao estabelecerem um "pacto ficcional", segundo Umberto Eco (1994), em Seis passeios pelos bosques da ficção. É dessa aceitabilidade que o texto ficcional se realiza para o leitor, o qual encontrará verossimilhanças, não verdades, e estará consciente da suspensão de uma relação direta com o seu mundo real.

As relações construídas com o texto fantástico, com efeito, acarretam perspectivas de distância e de recriações ainda maiores, pois é preciso crer que é pelo viés de uma construção insólita, impossível, que as significações se projetam. O encontro com o fantástico retira o leitor de suas certezas, forçando-o a, continuamente, reelaborar seus pressupostos acerca das correspondências com o que se crê como viável e, por que não, verossímil.

É a partir de um olhar dialético, formado por sequenciais dissoluções e reconstruções de sentido, que vemos nas narrativas da escritora gaúcha Veronica Stigger um relevante cenário para o trato do fantástico na literatura brasileira contemporânea. Seus textos conjugam o bizarro e o improvável em situações que, na composição ficcional, se tornam parte das relações entre as personagens e seus contextos. A ironia é uma das figuras mais importantes dessa composição: a autora "brinca" com o intratável, joga com as mazelas e miserabilidades, e as traduz numa banalidade constitutiva de nossa relação com o outro, inserindo nesses cenários uma mirada à condição trágica. Incômodas, impertinentes e deslocadas, essas personagens fantásticas nos questionam através de situações absurdas, e é pela ruptura com o possível que o paradoxo da literatura se perfaz.

\section{Absurdo e fantástico, encenações teóricas em Veronica Stigger}

Fazer uma seleção entre os contos de Stigger, para analisar o fantástico nessa escritura, é encontrar-se com uma série de possibilidades que, até quando se mostram menos insólitas, são atravessadas por circunstâncias bizarras. Desde seu primeiro livro, O trágico e outras comédias (2004), a aposta na criação de enredos absurdos confirma uma característica indissociável de sua escritura. Com efeito, algumas composições de personagem ganham relevo, como é o caso da reincidência de casais que parecem formar uma personagem contígua: as situações por eles experienciadas se projetam em duplicada e redimensionam nossa percepção acerca dessas experiências.

Eles aparecem em vários momentos, como em "Rotina" (2004), com o casal que estabelece um diálogo precário pela adivinhação dos sonhos do parceiro; "O cubículo" (2007), narrativa nonsense em que, oprimidos pelos abusivos aluguéis, ambos passam a viver no ânus do amigo; "Escada rolante" (2007), conto em que uma turista suíça tem seu corpo tragado ao subir a escada de um shopping, servindo-se de espetáculo ao marido que assiste à cena contemplativamente; 


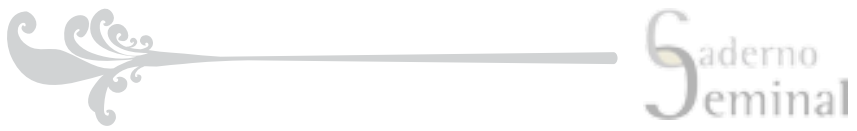

"200 m²" (2009), biografia fantástica da autora e seu esposo, na qual encenam uma performance do absurdo; "Os anões" (2009), na composição trágica de dois anões espancados até o desfalecimento pleno, numa confeitaria, além de "Tristeza e Isidoro" (2007) e "Curta-metragem" (2009), sobre os quais teceremos nossas considerações neste estudo.

"Tristeza e Isidoro" e "Curta-metragem" conduzem à releitura do "Teatro do Absurdo", principalmente em relação às personagens de Eugène Ionesco. Segundo a perspectiva do crítico teatral Martin Esslin³, o termo "absurdo" definiria peças cuja união entre comicidade e tragédia delineia a deriva como condição indissolúvel no trato das personagens, e as inserções da desolação e da incomunicabilidade do homem moderno rompem com a dramaturgia tradicional. Por outro lado, embora a ruptura seja a marca da novidade, são as inserções de elementos tradicionais que tornam essa tendência interessante, pois o retorno é trazido na diferença. Assim, como exemplo, vemos o resgate da comédia de nonsense (com falas, a princípio, desconexas); dos mimodramas (espetáculos gestuais surgidos na antiguidade greco-romana); da commedia dell'arte (gênero cômico entre os séculos XVI e XVIII) e do vaudeville (mescla de números musicais burlescos, cômicos e de dança).

O nonsense se sobressai como recurso de Veronica Stigger em grande parte dessas construções, e o diálogo com as personagens de Ionesco, como o Sr. e a Sra. Martin, da peça "A cantora careca" (1950) ${ }^{4}$, decorre de uma elaboração discursiva que, ao não se concretizar como mediadora de compreensões, provoca o espectador a reelaborar novos sentidos ao que Ihe é apresentado. Na cena IV, vemos o casal discutir se eles se conhecem ou não, e elementos que denotam a incomunicabilidade em questão são atribuídos às falas, gradativamente:

"(...) SR. MARTIN: Desculpe minha senhora, mas me parece, se não estou enganado, que a conheço de algum lugar.

SRA. MARTIN: Eu também, meu senhor, parece que o conheço de algum lugar. (...)

SR. MARTIN: Desde que cheguei a Londres, moro na Rua Bromfield, minha cara senhora.

SRA. MARTIN: Que curioso, que estranho! Eu também, desde a minha chegada a Londres, moro na Rua Bromfield, meu caro senhor. (...)

SR. MARTIN: Eu tenho uma filhinha, minha filhinha, ela mora comigo, minha cara senhora. Ela tem dois anos, é loira, tem um olho branco e um olho vermelho, é muito bonita e se chama Alice, minha cara senhora.

SRA. MARTIN: Que estranha coincidência! Eu também tenho uma filhinha, ela tem dois anos, um olho branco e um olho vermelho, é muito bonita e também se chama Alice, meu caro senhor.

SR. MARTIN: [com a mesma voz arrastada, monótona] Que curioso e que coincidência! E estranho! Talvez seja a mesma, minha cara senhora!

SRA. MARTIN: Que curioso! É bem possível, meu caro senhor. (...) (IONESCO, 1999, p.27)"

3 Esslin não fala de movimento teatral, mas sim de uma tendência verificada no final dos anos cinquenta, no contexto Pós-Guerra.

4 A edição presente neste artigo é a de 1999, publicada pela editora Papirus. 
Ao termino da cena, é pela descoberta das personagens - são casados - que se verifica a inscrição do absurdo, uma vez que é preciso aceitar a proposta de encenação como construtora de sentidos não aparentes no texto escrito. Assim, o que não é dito precisa das inferências operadas pelos leitores/espectadores. $\mathrm{Na}$ há dúvidas de que se trata de uma inter-relação cômico-trágica; a ironia viabiliza a proposta crítica de Ionesco, quanto ao desconhecimento do outro tão próximo, com o qual já não parecem mais possíveis quaisquer partilhas de entendimento.

Em "Tristeza e Isidoro", título que conduz a uma inevitável referência à imprecisa lenda medieval ${ }^{5}$, o questionamento do diálogo/discurso, como construtor de sentidos entre as personagens, revela que algumas mediações são inviáveis, pois a comunicação parece interrompida, inconclusa e, sobretudo, codificada por códigos desconhecidos, a princípio. O reconhecimento desse impasse faz-se ainda mais latente em decorrência dos gêneros imbricados nessa composição híbrida de textos que são apresentados como "contos", como no caso da peça-conto em análise, a qual, no livro, traz a legenda: "Drama, ato único" (STIGGER, 2007, p. 82).

Como no texto teatral, são pelas rubricas que temos acesso ao contexto em que as personagens tecem seus diálogos. Neste caso, um acidente automobilístico inicial é o mote para a composição cênica emergente do caos, aos cacos. Em vão, Tristeza e Isidoro tentam atabalhoadamente uma conversa capaz de solucionar a saída do veiculo acidentado. É neste momento que vemos a conjunção de elementos provenientes do Teatro do Absurdo em enclave com as teorias a respeito da literatura fantástica. E, se as falas denotam incompreensões, religando a autora a lonesco, a série de pequenos incidentes decorrentes desse diálogo impossível nos remete às narrativas de Kafka; o improvável é elevado à condição de protagonista, atuando junto às personagens, conduzindo suas ações. O acidente inicial vai perdendo sua perspectiva de marcação nas cenas que o sucedem, e outras situações insólitas parecem convergir nesse contexto.

Concomitantemente ao desespero entoado por Tristeza, ao sentir a porta cair sobre os seus dedos numa das bizarras tentativas de sair do carro, Isidoro canta canções de bossa nova em que o nome da mulher aparece, misturando-as com gargalhadas. Uma série de novos machucados se processa e, quando o leitor espera pelo final trágico de um dos dois, senão de ambos, um novo ciclo de situações estranhas se inscreve. Ainda que este leitor vacile sobre as certezas quanto às possibilidades de sobrevivência, ele precisa aceitar que as personagens saem do carro com vida, bem como uma gravidez - mostrada somente no final - que não inviabiliza um sem números de contorcionismos, dentro de um espaço exíguo, desempenhados por Tristeza durante o texto. Além disso, é necessário pactuar com a não revelação do motivo pelo qual não podem acionar a polícia, suspendendo, assim, um desfecho capaz de explicar a tensão do casal que parece

5 Embora reconheçamos que a escolha do título não seja fortuita, o enredo de "Tristeza e Isidoro" não propõe relações com as histórias concernentes à lenda de Tristão e Isolda. No presente texto, isso funciona como um jogo com os nomes das personagens e, sobre essa inversão, incide mais uma possibilidade de ruptura dos signos. 


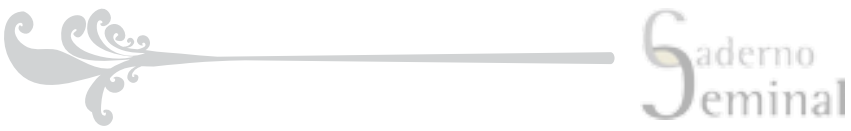

fugir de alguém. A peça-conto termina com os dois fora do veículo, e Tristeza contando histórias trágicas que Isidoro desconhece, porém ouve deitado sobre seu colo. Assim, as "bizarras canções de ninar" ratificam a incomunicabilidade, marca da relação entre as personagens e o mundo do qual elas fogem.

O acidente se torna banal, atribuído de elementos estranhos, cujas construções na ficção são modeladas pela ironia e pelo que de menos usual delas seja possível prever, além de forçarem a recomposição de cenários fantásticos, onde o impossível conduz os elementos ali presentes, suspendendo-os, distorcendoos, para mostrar sentidos pelo avesso. Tristeza e Isidoro podem ser lidos pelo que neles há de insólito, termo que, em Stigger, revigora a ideia do paradoxo da literatura (recuperando as palavras finais de Todorov) e confirma um investimento no absurdo, compreendido como algo desmedido e fora do tom (do latim: $a b$-, aquilo que deflagra, e surdus, que não pode, não quer ou não deve ouvir).

A interação (entre si e com os contextos e espaços) só pode ser compreendida pelo nonsense e pela imagem advinda dos espetáculos de vaudeville, sobretudo no que tange à representação do "Circo dos horrores"; o aspecto humano é delineado por sua possibilidade caricatural inscrita na aberração. Distantes de um olhar moralizante, o que vemos nessa inversão de projeção valorativa é uma possibilidade de narrar o espanto, percurso que traz, à cena literária contemporânea, a inserção de um olhar - pela fenda - ao incômodo, através de questionamentos inevitáveis às miradas de um leitor atento e disposto à aceitação das mediações propostas no texto.

Em "Curta-metragem", temos uma divisão em duas partes, as quais se conectam para reafirmarem estranhezas em reciprocidade e consequência. Escrita como um roteiro cinematográfico do gênero que dá nome ao conto (também sublinhado por hibridizações), a história referente à primeira parte começa com uma cena apta à reprodução corriqueira de uma relação a dois, não fosse pelo que se anuncia ao leitor: "Ele, então, coloca a perna direita sobre a murada da sacada, projeta o corpo para frente e diz a ela, sorrindo. ELE: Olha só." (STIGGER, 2009, p. 15-16). A aceitabilidade do insólito é requisitada continuamente, e tonifica a percepção do improvável: "ELA: Você podia, pelo menos, trocar essa calça. Ela volta a assistir à televisão. A câmera retorna a ele e se aproxima até focá-lo em plano americano. Ele se joga da sacada." (STIGGER, 2009, p.16). Ao vêlo estendido sobre a calçada, seus óculos caem e, novamente, é introduzida no texto a linguagem do cinema, indicando a posição da câmera, que sai do plano americano (enquadre do joelho para cima), para a projeção de imagens turvas, fora de foco, sugerindo que a mulher também tenha se atirado, ação posteriormente confirmada na descrição da cena.

Como continuação, na segunda parte, "Curta-metragem II", a proposta imagética recupera o universo das animações infantis: "A imagem vai aparecendo 
gradualmente, do centro para as bordas, como em alguns desenhos animados antigos." (STIGGER, 2009, p. 48). A inserção dessas referências recria a aposta no nonsense, assim como em "Tristeza e Isidoro", confirmando a ruptura como mediadora de significados. Após a descrição cênica, aparece o casal, um sobre o outro, conversando acerca da quebra dos óculos, cujas lentes israelenses haviam custado muito caro. Embora eles pouco consigam movimentar-se, é da irrupção de um diálogo aparentemente impossível àquele contexto que emerge o aspecto cômico, além de estabelecer com o leitor a concordância de que não seja dita a altura em que se deram as quedas, informação fundamental para o deslinde das probabilidades de sobrevivência.

Suspensas as referências requeridas pelo mundo real, a impressão de estranheza permanece irredutível, corroborando a inscrição do fantástico, pois a sequência das falas sugere que a queda tenha sido deletéria a "ELE", que passa a não sentir as próprias pernas, após o salto de "ELA". O término reforça o contexto insólito: estendido na calçada, o casal espera um fusca passar, a fim de confirmar "o mito do fusca" (sempre que este veículo aparece, outro o procede), mencionado pela mulher. Incompreensíveis, diálogos e personagens denotam propósitos desconexos e inviáveis, contudo, é de uma perspectiva capaz de coadunar absurdo e fantástico, que o leitor aceita o impossível como possibilidade. Na construção de situações estranhas (concernentes ao universo do fantástico, e não do estranho como gênero, como propõe Todorov), Stigger convoca seus leitores à aceitabilidade do incômodo, tão presente na imprecisão de seus enredos. O leitor continuamente é provocado à disposição de novos sentidos, à troca de lugares que, como numa dança das cadeiras, depende de sua atenção e agilidade para não ficar fora do jogo.

\section{O fantástico como diferença}

No cenário da literatura brasileira contemporânea, não tem sido raro a presença de autores cuja aposta no insólito parece escrever uma característica de nosso tempo. Ao lado de escritores como Santiago Nazarian, Joca Reiners Terron, Ana Paula Maia, João Paulo Cuenca e Cecília Gianetti, apenas para citar alguns nomes em que podemos verificar uma proposta de ruptura, bem como de elementos estranhos inseridos em suas narrativas, vemos, em Veronica Stigger, essa aposta sublinhar sua escritura. Não se trata aqui de uma incidência episódica, mas sim de um traço presente na maioria de suas narrativas. A ironia em relação à nossa capacidade de compreensão do real conduz à leitura desses elementos revelados por uma crença no impossível como possibilidade na trama ficcional.

Distantes de uma perspectiva alegórica ou maravilhosa, os traços que revelam o fantástico nessas composições decorrem do que Todorov considera a respeito da necessária inserção da estranheza, pois 'sem 'acontecimentos estranhos' 


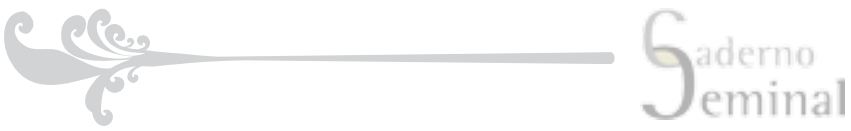

o fantástico não pode nem sequer dar-se. O fantástico não consiste por certo nesses acontecimentos, mas estes são para ele uma condição necessária." (TODOROV, 2003, p. 136). Logo, verificamos, nas narrativas da autora, uma elaboração simples e direta no trato dessa condição, a qual conjuga espanto e perplexidade frente às relações das personagens com aquilo que lhes é apresentado como realidade na ficção. Não há explicações viáveis à inserção de fenômenos sobrenaturais, bem como não se encontram engendramentos alegóricos: tudo é direto, com uma precisão de sentidos distorcidos, próprios de um forte desejo de imprecisão e subversão do real.

Não é por acaso que, em Ficção brasileira contemporânea (2009), Karl Erik Schollhammer compara algumas transfigurações propostas por Stigger a Kafka, em $A$ Metamorfose (1915) e ao que o escritor argentino Cesar Aira diz sobre Raúl Damonte Botana, mais conhecido como Copi. Em relação à primeira comparação, Karl Erik escolhe como corpus de sua análise a narrativa "Marta e o minhocão", de Gran cabaret demenzial. O paralelo entre Stigger e Kafka é constituído pela inserção do elemento fantástico que, em ambos os contextos, é tratado com naturalidade pelas personagens. Assim como o inseto de $A$ Metamorfose, o extravagante minhocão, habitante da casa de Marta, força o reconhecimento do real através do que se mostra pelo fio da estranheza e, como afirma Karl Erik "a realidade ganha dimensões fantásticas e suprarreais". (SCHOLLHAMMER, 2009, p. 158).

O absurdo como proposta comparativa decorre da menção a Copi, escritor e dramaturgo argentino do século XX, integrante da companhia de teatro "Grupo do Pânico", ao lado do dramaturgo espanhol Fernando Arrabal, uma das principais referências ao Teatro do Absurdo, juntamente com lonesco, Samuel Beckett, entre outros. Ao citar o livro Copi (AIRA, 1991), Karl Erik destaca a importância da percepção artística no trato de autores como Copi e Stigger, e propõe uma conclusão que recupera a ideia do paradoxo da literatura a que se refere Todorov, mencionado no início do presente artigo: "a felicidade abandona o campo do possível, onde foi enquadrada pela compreensão comum, para se instalar na realidade do estranho, com tudo o que traz de absurdo e extravagante." (SHOLLHAMMER, 2009, p.158).

Essa recorrente menção ao estranho torna-se relevante para algumas reflexões acerca do termo, recuperando seu conceito em Freud, ora em diálogo com o que Todorov nos propõe sobre sua relação com o gênero fantástico. De acordo com as diferenciações estabelecidas no terceiro capítulo ("O Estranho e o Maravilhoso") de Introdução à literatura fantástica, Todorov considera que o fantástico deva ser tratado como um gênero capaz de abarcar sub-gêneros, nos quais estaria presente o estranho, bem como o maravilhoso, sem excluir a possibilidade de textos em que tanto um quanto o outro apareceriam "puros". No tocante ao "Fantástico-estranho", ele destaca: 
"Os acontecimentos que com o passar do relato parecem sobrenaturais, recebem, finalmente, uma explicação racional. O caráter insólito desses acontecimentos é o que permitiu que durante comprido tempo o personagem e o leitor acreditassem na intervenção do sobrenatural. A crítica descreveu (e frequentemente condenou) esta variedade com o nome de 'sobrenatural explicado'." (TODOROV, 2003, p.38).

Como exemplo dessas narrativas, ele menciona O manuscrito de Saragoça (1812), de Jan Potocki. Nesta narrativa em que se conjugam mistérios e elementos provenientes da cabala, o leitor imerge num universo onírico, decorrente de circularidades que irrompem o enredo, para trazerem à cena a inserção de projeções sobrenaturais. Entretanto, é da explicação racional desses "milagres", segundo Todorov, que o gênero "fantástico-estranho" se produz. E, após diversas diferenciações sobre o que o crítico considera como "estranho puro", ele afirma: "o estranho não cumpre mais que uma das condições do fantástico: a descrição de certas reações, em particular, a do medo. Relaciona-se unicamente com os sentimentos das pessoas e não com um acontecimento material que desafia a razão." (TODOROV, 2003, p.40).

Logo, a partir dessa minuciosa análise, algumas questões sobre os gêneros enviesados na costura ficcional de Stigger parecem romper com esse esquema, ao proporem, assim como suas narrativas, um olhar conceitual que permita novos sentidos à teoria sobre a incidência do texto fantástico. O estranho, a que tantas correspondências verificamos em seus textos, remete-nos à dubiedade do termo em Freud, em "Das unheimlich" (1919). Como já tratado pelo próprio autor, a traduzibilidade desse conceito é bastante complexa, uma vez que as possibilidades lexicais da língua alemã fazem com que as palavras se envolvam por aspectos filosóficos, como neste caso. Desta forma, o conceito de "estranho" traduziria, concomitantemente, aquilo que é - e não é - familiar, daí o incômodo, o desconforto. Em Stigger, ao se confrontar com recriações de contextos banais, mas tangenciados pela ruptura com o real, o leitor tem em mãos uma narrativa que suspende suas conjecturas: tudo pode acontecer, como algo natural, muitas vezes apresentado como único desfecho plausível e verossímil frente a tantas situações escabrosas e insólitas.

Morar no ânus do amigo; ser engolida pela própria contemplação do umbigo; ver uma repentina chuva de variados tamanhos e formas de pênis; retirar o Papa de uma privada sugadora; ter a cabeça cortada por um descuido e permanecer como espectador de uma peça de teatro, ou ter o corpo multilado durante um bizarro passeio cronometrado com o namorado ${ }^{6}$ são apenas alguns dos exemplos que, ao lado de "Tristeza e Isidoro" e "Curta-metragem", nos levam a refletir acerca de uma construção fantástico-absurda. A junção desses gêneros conecta Stigger às narrativas nas quais experienciamos a estranheza,

6 Respectivamente, os enredos fazem referências aos contos: "O cubículo" (2007), "Janice e o umbigo" (2004), "A chuva" (2004), "Sheila e Miguelão" (2007), "No teatro" (2004) e "Domitila" (2007). 


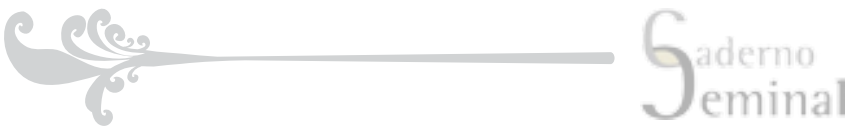

ao mesmo tempo em que vemos a convergência de diálogos que remontam aos textos dos dramaturgos do absurdo.

A elaboração literária insere em sua composição escrita uma perspectiva discursiva proveniente da incomunicabilidade entre as personagens, sem, porém, anular a compreensão de um discurso hábil à construção de sentidos às avessas, em consonância com os contextos da autora. O fantástico atua, assim, nas situações insólitas, e o absurdo, na projeção cênica das falas proferidas pelas - e sobre - as personagens, encenadas como artifícios que Stigger encontra para quebrar ainda mais com nossas certezas quanto aos limites do bizarro nessas narrativas.

Autora e textos respondem ao que Karl Erik afirma sobre alguns escritores brasileiros contemporâneos, no que tange à relação própria de uma ruptura com a realidade histórica reconhecível. Segundo ele, "a realidade não é objeto exterior à ficção, mas a potência de transformação e de criação que nela se expressa." (SCHOLLHAMMER, 2009, p. 159). Essa potência de transfiguração/transformação na escritura de Stigger evidencia um intento literário que, ao coadunar enredos fantásticos ao absurdo, desvela o paradoxo tão caro à literatura. Como leitores, vemos possibilidades de existência para as suas situações maquinadas na impossibilidade. E é aí, onde tudo parece em desencaixe, que as peças nos questionam e, por inúmeras vezes, debocham de nossas (in)certezas.

\section{Conclusão}

O encontro com os textos de Veronica Stigger, sem dúvidas, conduz-nos a alguns questionamentos acerca do que experienciamos como leitores. Desde o princípio, é preciso entrar nesse "bosque", a que se refere Umberto Eco, disposto ao contorcionismo de suas personagens, exercitando com elas a recriação de sentidos para o que se mostra em estado de dissolução. Fragmentadas as certezas sobre o que iremos encontrar, pois no mundo de Stigger tudo pode acontecer, aceitamos que aquilo projetado na inverossimilhança possa - e deva - ganhar significados em ruptura, sempre dispostos a novas ressignificações.

Assim como suas personagens podem sofrer quaisquer metamorfoses, o texto, como objeto literário, também traz a reboque uma capacidade de hibridização conceitual, alinhando-se aos pressupostos do texto fantástico e aos procedimentos discursivos decorrentes do Teatro do Absurdo.

Com efeito, a formação de Stigger - crítica literária e professora de história da arte - contribui para o trânsito livre e, por que não, despretensioso, entre perspectivas teóricas, auxiliando-a para que essas inserções sejam traduzidas em narrativas que, ambivalentemente, incomodam e provocam gargalhadas em seus leitores. Suas histórias são cômicas, escandalosas, tonificadas pela infinidade de palavrão que, como diz Karl Erik, é "usado e abusado com a 


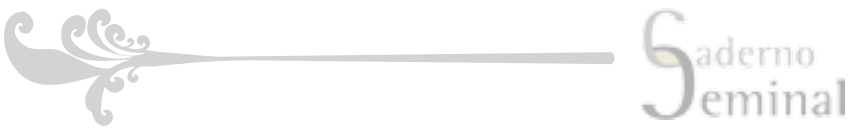

alegria de uma criança que descobre a força da palavra proibida e insiste nela até o esgotamento." (SCHOLLHAMMER, 2009, p. 156).

Debochada, irônica e mordaz, vemos nessa escritura uma junção de conceitos e brincadeiras correspondente ao texto de fruição a que se refere Roland Barthes, em O prazer do texto (1973). É quando tudo parece sem sentido, sem propósito, que somos forçados à reelaboração de nossas crenças, inclusive sobre nossas projeções no trato do texto de ficção. E, nesse "deixar levar-se", o fantástico e o absurdo conduzem os leitores à experimentação de circunstâncias nas quais o bizarro é natural, e o insólito se configura como matéria essencial à fabulação de novos sentidos. O texto de prazer surge no "momento em que meu corpo vai seguir suas próprias ideias - pois meu corpo não tem as mesmas ideias que eu". (BARTHES, 1973, p. 24) e, juntos, experienciaremos o paradoxo como mote, mediação e desfecho.

\section{PERFORMANCES OF THE FANTASTIC AND ABSURD IN VERONICA STIGGER}

\section{ABSTRACT:}

This article is an analysis proposal of two tales of Veronica Stigger, considering the fictional creation of contexts by proposing a severe break with reality, conduct the reader to meet a fantastic writing. To achieve this aim, the texts "Tristeza e Isidoro", of Gran cabaret demenzial (Cosac Naify, 2007) and "Curtametragem", script-tale in two parts of Os anões (Cosac Naify, 2009) form part of this study. Based on the idea that in these constructions there is a distrust of dialogue as the possibility of interaction between the characters, is noticeable the development of other viable ways of affective mediations to these scenarios that somehow suggest the concept of uncanny. In this perspective, it is noticed also a proximity between the Stigger's narrative universe and the Theater of the Absurd, in which the insertions of desolation and incommunicability of modern man break with the traditional dramaturgy and set new directions. Inside out, the characters present here experience the chaos and act out precarious forms of survival among accidents, falls and pieces.

\section{KEYWORDS:}

Rupture; fantastic; absurd; contemporaneity. 


\section{REFERÊNCIAS}

BARTHES, R. O prazer do texto. Tradução de J. Guinsburg. 5aㅗ edição. São Paulo: Perspectiva, 2010.

ESSLIN, M. The theater of the absurd. Londres: Randon House IC, 2004.

FREUD, S. Lo siniestro. In: Obras Completas. Tomo III. Trad. Luis Lopes Ballesteros y de Torre. Madrid: Biblioteca Nueva, 1981.

IONESCO, E. A cantora careca. São Paulo: Editora Papirus, 1999.

SCHOLLHAMMER, K. E. Ficção brasileira contemporânea. Rio de Janeiro: Civilização Brasileira, 2010.

STIGGER, V. O trágico e outras comédias. Rio de Janeiro: 7 Letras, 2004.

_-_-_-_. Gran Cabaret Demenzial. Rio de Janeiro: Cosac Naify, 2007. . Os anões. Rio de Janeiro: Cosac Naify, 2009.

TODOROV, T. Introdução à literatura fantástica. Coleção Debates 98. 2ª edição. São Paulo: Perspectiva, 2003. 